\title{
Editorial
}

\section{Transforming Higher Education Teaching and Learning Environments - Introduction to the Special Issue}

\author{
Erkko Sointu \\ University of Eastern Finland \\ Joensuu, Finland \\ https:/ / orcid.org/0000-0003-4001-7264 \\ Laura Hirsto \\ University of Helsinki/University of Eastern Finland \\ Helsinki/Joensuu, Finland \\ https://orcid.org/0000-0002-8963-3036 \\ Mari Murtonen \\ Tampere University \\ Tampere, Finland \\ https://orcid.org/0000-0003-2381-5731
}

To facilitate meeting the requirements of student-centered learning in the $21 \mathrm{st}$ century, it is important to strengthen higher education teachers' digi-pedagogical skills, and to consider novel ways of teaching and learning. This necessitates the development of pedagogical thinking, technical infrastructures, and learning environments. The obvious need for meeting the needs of 21st century learning comes from changing societal expectations as the knowledge society itself and the labor market are undergoing considerable change. This means that teachers need to consider new ways of teaching, as well as novel ways the utilizing technology in their work and in learning environments. Moreover, the learning of the content itself is increasingly insufficient as learning generic (e.g. Pitman \& Broomhall, 2009) or 21st century skills (e.g., Voogt \& Pareja Roblin, 2012) such as collaboration, technological proficiency and creativity grow in importance. Thus, novel ways of considering and developing higher education teaching, learning and learning environments are required. Importantly, for these tasks, rigorous assessment and research are needed to consider the outcomes and future orientations in the higher education development as well as in informing policy at various levels. 
Therefore, this special issue of IJLTER explores and outlines a wide array of research and practices around digi-pedagogical teaching and learning for the 21st century teaching, learning and learning environments. The articles of this Special Issue are based on an international call for the papers presented in Finnish Education Research Association (FERA) 2019 preconference Enhancing digi-pedagogical skills of higher education staff and change of learning environments, which took place in the fall of 2019 at the University of Eastern Finland in Joensuu, Finland. The guest editors of the Special Issue represent scholars from around Finland involved in ongoing collaboration for the higher education community. The seven original contributors of this Special Issue represent contentual, geographical and methodological diversity of the higher education community in Finland and internationally. We trust that the content of this special issue is of considerable interest to practitioners and researchers who seek new insight into higher education.

In developing higher education, more and more focus has been placed on developing university teachers' pedagogical skills. The challenge lies in ensuring that the pedagogical insight reaches the variety of teachers working in various roles and positions in the university. Traditionally university pedagogical education has been aimed at the official teaching staff, while other groups, such as doctoral students, international visiting scholars or people in full time research positions, have been left out. Further, a tendency to offer only face-toface contact teaching has not served all groups well. This is the issue which is tackled in the first article of this special issue by Murtonen, Laato, Lipponen, Salmento, Vilppu, Maikkola, Vaskuri, Naukkarinen, Virkki-Hatakka, Pajarre, Selänne, and Skaniakos. In their article Creating a national digital learning environment for enhancing university teachers' pedagogical expertise - the case UNIPS they describe their endeavors in developing an easily reachable digital platform through which universities could collaboratively support the pedagogical development of their teachers, researchers, administrative personnel and international staff. By careful collaborative planning, based on the results gained from higher education teaching and learning research, and by drawing on student feedback immediately, it was possible to create a learning solution that fulfilled the needs of Finnish higher education system.

The second article by Vuojärvi, Eriksson and Vartiainen, Cross-boundary Collaboration and Problem-Solving to Promote 21st Century Skills-Students' Experiences goes deeper into the process of developing the pedagogical design of a higher education course through an iterative design-based development process. In the article, research about an ongoing design-based research initiative is reported. During the research, the authors designed a forest bioeconomics course in a higher education context in which students from various institutions could participate. In their article, they investigate especially students' experiences of how cross-boundary collaboration and problem solving promote the learning of 21st century skills. The course that the research focuses on was designed with the frameworks of 21st century skills in mind. Ideas of problem solving cross-boundary teaming as well as online and blended learning was used to form a supportive learning environment. The design of the course is described in detail, and the results of the pilot course seem very interesting. The 
students experience that cross-boundary collaboration, in which students came from various fields and engage in joint problem solving, may support learning in differing ways. In comparing the blended and online course versions, an expected difference was that the drop-out rate of the online course was remarkably higher, but students in both courses were able to succeed in the development challenge -assignment. Vuojärvi et al. suggest key issues that have to be considered when designing this kind of a course which may have further significance as more authentic learning environments are designed for higher education students during their studies.

In addition to developing teachers' teaching skills, universities and higher education institutions need to focus on curriculum development (cf. Barnett and Coate, 2005; Hirsto \& Löytönen, 2011; Hirsto, 2013). The next three articles in this special issue focus on the widely used Flipped Classroom pedagogical approach and university students' experiences and achievement within such learning contexts. These three articles are related to an educational development project in which university teachers were systematically supported in transforming their courses to align with the Flipped Classroom approach. The Flipped Classroom approach seems to show positive impact in general, but the results are not unambiguous. Guo (2019) suggests that the ambiguous results rest on the wide variation in how Flipped Classroom has been implemented.

One of the challenges in developing university education is how to develop university teachers' pedagogical skills. The next three papers draw on a project in which university teachers were supported in concrete ways to plan and execute their FC courses. This design of the education is described in the article Key components of learning environments in a successful flipped course by Hyypiä, Sointu, Hirsto, and Valtonen. Hyypiä et al. analyze participants' experiences across a number of courses. Drawing on a mixed-methods approach, they investigate various components that influence positive learning experiences in higher-education flipped classroom (FC). In their investigation, FC was approached from learning environment perspectives including pedagogical dimensions, social and collaborative dimensions, as well as technological aspects. The results of the FC courses are presented from multiple discipline perspectives with data $N=414$ students. For the analysis, the sample was divided into three groups of learning experiences. Based on both quantitative and qualitative results, pedagogical and social factors seem to influence students' views of a successful FC learning environment most. Hyypiä et al. consider teachers as centrally important in facilitating successful FC courses as their knowledge, choices and actions influence how students experience the flipped classroom.

The second article related to the Flipped Classroom approach is by Hyppönen, Hirsto, and Sointu. In their article Perspectives on university students' selfregulation, task-avoidance, time management and achievement in flipped classroom contexts, they investigate how university students' self-regulated learning skills are related to their achievement in general over a number of Flipped Classroom courses. With a total of 230 students, the article investigates how self-regulation 
of learning, time-management, lack of regulation, and task-avoidance are related to students' self-regulation of learning, and how these were related to academic achievement. Based on the results, students with high task avoidance in addition to generally low skills in self-regulation, are less successful in terms of academic achievement in flipped classroom contexts.

The final of the three Flipped Classroom articles concerns teacher education students' experiences through mixed-method research. In the article Exploring Students' Experiences of Self-regulation during a Large Flipped Classroom Course in Teacher Education, Hirsto, Väisänen, and Arffman investigate issues related to self-regulation and self-regulated learning during three consecutive courses of advanced pedagogical studies of teacher education students named Education for sustainable future, which was a 5 ECTS course. The results indicate that students come to this kind of course with various goals and interests, and these are related to their experiences of the teaching-learning environment in various ways. Furthermore, teacher students seem not to set clear goals for their studying on the course level, but according to Hirsto et al., broader teacher education preferences seem to be related to their experiences of the teachinglearning environment. Hirsto et al. suggest that students' interest in the course seem to be quite persistent as the original interest were related to the level of interest at the end of the FC course. This may refer to the need for more elaborate pedagogical means of supporting goals setting and explicit scaffolding of self-regulated learning processes during these kinds of Flipped Classroom courses.

Sixth article in this Special issue focuses on teachers' perspectives about digital transformations in higher education. In their article University teachers' ambivalence about the digital transformation of higher education, Sjöberg and Lilja investigate university teachers' experiences of digital technology implementation. They consider as education developers the use of technology to be complex matter in which pedagogical, content related, and technology aspects strongly intertwine together. For this task, they use Technological Pedagogical Content Knowledge (TPACK) framework for highlighting competences and knowledge of teachers. The topic of the paper is interesting, particularly as it considers university-level teachers. The paper includes two studies, one focusing on digital competences with survey and other presenting focus group interviews. Based on the results, teachers seem to be hesitant still positive towards using digital technology in their pedagogical practice. However, the integration of technology in teaching is connected to organizational and societal processes beyond their direct control, and this produces some ambivalence in their practices. Sjöberg and Lilja conclude that that one-sided theoretical assumptions about technology integration may be an explanation for a situation where the practice and the rhetoric of technology use in higher education diverge.

The final article of this compilation takes a broader outlook on the development of teaching and learning of Finnish universities. Pyykkö, Vuorinen, and VuorioLehti, in their article Government Key Projects (GKP) as a Tool for the Development of 
Learning and Teaching in Finnish universities presents strategic, national guidance of higher education development from various different perspectives. They explore goals set for and the backgrounds used for the national higher education policy and state steering of higher education. The authors also concentrate to the role of university education leadership. In addition, they concentrate on one funded government key project (GKP), the role of the steering group in this GKP and consider future possibilities for government steering. The official Finnish Government and the Ministry of Education and Culture documents as well as a questionnaire to the GKP Steering Group members are used as research materials. The paper by Pyykkö, Vuorinen and Vuorio-Lehti offers an important explanation for national-level, university-level and project-level decisionmaking, steering and outcomes. Moreover, authors present a unique set of results and discussion for the future of higher education development.

\section{Acknowledgments}

We are deeply grateful to the 15 researchers who served as (double-blind reviewers for the manuscripts proposed for this special issue, offering constructive and detailed feedback. We would also like to thank M. A. (Ed.) Jenni Kankaanpää for going through and revising the technical issues and format of the manuscripts. We would like to sincerely thank the Finnish Ministry of Education and Culture and Finnish who supported our key convergent project applications Strengthening the pedagogical and digital skills of staff in higher education [Grant no. OKM/199/523/2016] and Developing researchbased practices for facilitating peer-group mentoring -Verme2 [Grant no. $\mathrm{OKM} / 42 / 523 / 2017]$.

\section{References}

Barnett, R., \& Coate, K. (2005). Engaging the Curriculum in Higher Education. Maidenhead, England: McGraw-Hill/Open University Press.

Guo, J. (2019). The use of an extended flipped classroom model in improving students' learning in an undergraduate course. Journal of Computing in Higher Education, 31, 362-390. https://doi.org/10.1007/s12528-019-09224-z

Hirsto, L. (2013). Palautepohjainen opetuksen kehittäminen ja laatu. [Feedback-based educational development and quality] In J. Hakala \& K. Kiviniemi (Eds.), Vuorovaikutuksen jännitteitä ja oppimisen säröjä. Aikuispedagogiikan haasteiden äärellä (pp. 147-162). Retrieved from

https://jyx.jyu.fi/dspace/bitstream/handle/123456789/48383/978-951-395376-8.pdf?sequence $=1$

Hirsto, L., \& Löytönen, T. (2011). Kehittämisen kolmas tila? -Yliopisto-opetus kehittämisen kohteena [A third space for development? -Developing university teaching]. Aikuiskasvatus, 31(4), 255-266.

Pitman, T., \& Broomhall, S. (2009). Australian universities, generic skills and lifelong learning. International Journal of Lifelong Education, 28(4), 439-458. doi: $10.1080 / 02601370903031280$

Voogt, J., \& Pareja Roblin, N. (2012). A comparative analysis of international frameworks for 21st century competences: Implications for national curriculum policies. Journal of Curriculum Studies, 44(3), 299-321. 


\section{Biographies}

\section{Erkko Sointu}

Erkko Sointu (PhD, Education) is a tenure-track assistant professor of learning and novel teaching method development in the School of Educational Sciences and Psychology at the UEF. His research interests lie in the utilization and students' perceptions of flipped classroom/learning (FC/L), technology in education, and strength-based approaches in basic education. He has been responsible for large-scale training in FC/ $\mathrm{L}$ for higher education teachers at UEF and also at other universities in Finland and internationally. He is also a trained teacher with experience in both comprehensive and higher education.

\section{Laura Hirsto}

Laura Hirsto (PhD, Educational psychology) is a research director and had been appointed to a professorship in the School of Applied Educational Science and Teacher Education at the UEF, and she is a senior lecturer in university pedagogy at the Higher Education Development Center at the University of Helsinki. Her research interests lie in the studying, learning and motivational processes of higher education students, teacher training, and the research-based development of teaching and learning environments (including FC/L approaches) in various contexts. She is also a trained teacher with experience in both comprehensive and higher education.

\section{Mari Murtonen}

Professor of Higher Education Pedagogy, Faculty of Education and Culture, Tampere University, and a Research Leader of the UNIPS solution at the University of Turku during 2017-2019. Her research interests are in higher education learning and teaching, especially in how to foster students' development of scientific thinking and teachers' pedagogical expertise in different environments. 